\title{
$50(2010)$
}

\section{The height-weight index of the newborn infant.}

\section{By RICHARD E. SCAMMON.}

[From the Department of Anatomy, University of Minnesota, Minneapolis, Minnesota.]

The material used in this study consisted of the records of the heights (or lengths) and weights of some 4,200 living newborn children from a number of European clinics. The lengths were all in centimeters, the weights in grams. The cases were grouped according to their lengths in centimeter intervals, the group of shortest infants including those from 47 to $48 \mathrm{~cm}$. and the group of longest cases including those from 56 to $57 \mathrm{~cm}$. in length. The males and females of each group were considered separately. The average weight and the standard deviation, the probable error and the coefficient of variability of the weight were determined for each group. The ponderal or height-weight index of the average weight for each group was also worked out according to the formula :

$$
\text { P. I. } \frac{\text { Weight }}{\text { Height } 3} \times 1000 \text {. }
$$

These indices were determined both on the pound-inch (avoirdupois) and the centimeter-kilogram (metric) basis. The results obtained are shown in part in the graph below and may be summarized as follows:

(1) With the increase in total body length in the latter part of prenatal life the height-weight index drops slowly, there being a decline of 1.5-2.5 per cent. (avoirdupois index) or 0.4-0.8 per cent. (metric index) between the average for $47 \mathrm{~cm}$. and that for $50 \mathrm{~cm}$. of total body length. In infants over $50 \mathrm{~cm}$. in total body length the index declines much more rapidly, falling from an index of the average of 89.50 per cent. for males and 88.12 per cent. for females (avoirdupois) at 50 to $51 \mathrm{~cm}$. to one of 79.91 per cent. for males and 80.08 per cent. for females at 56 to $57 \mathrm{~cm}$. of body length. The drop in the metric index for the same period is from 25.99 per cent. to 22.94 per cent. for the males and from 25.60 per cent. to 23.24 per cent. for the females. This agrees with Bardeen's findings ${ }^{1}$ that longer newborn infants

1 Bardeen, C. R., Publ. 272, Carnegie Inst. of Washington, 1919. 
are relatively lighter than shorter ones, although the values are slightly below those reported by Bardeen. It seems significant that this drop is accentuated after the infant reaches the length of $50 \mathrm{~cm}$. which is generally regarded as a criterion of the completion of the normal span of intrauterine life. Since the ponderal index drops very rapidly with increasing length after 50 $\mathrm{cm}$. the usual empirical formulæ for body length and body height in the fetal period will not hold for these longer infants.

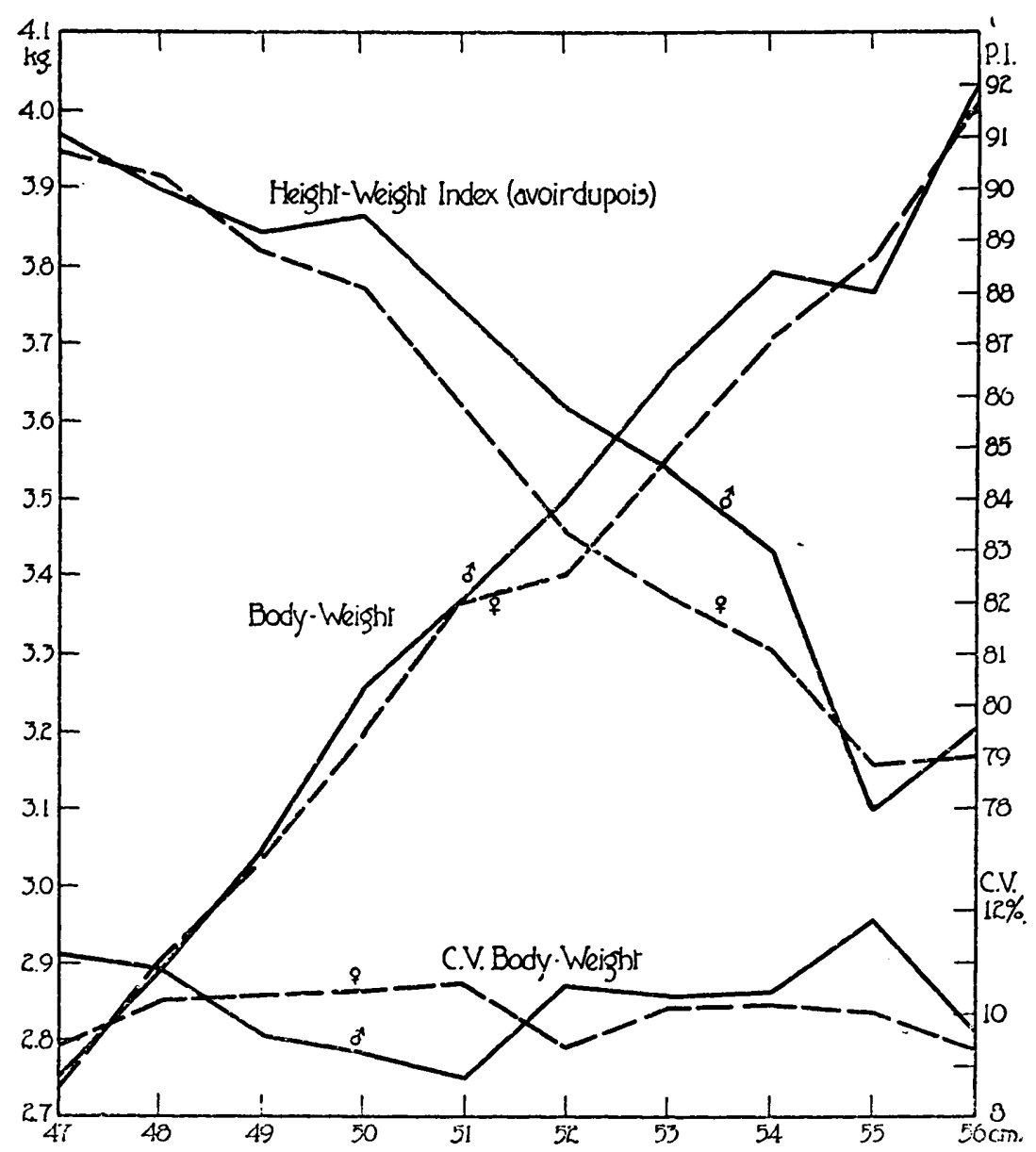

A graph illustrating the relation between body length (or height) and body weight in a series of 4,208 living, new-born children. The curves show the average body weight, the coefficient of variability of body weight and the height-weight index for centimeter intervals of body length from 47 to 57 $\mathrm{cm}$. The males are indicated by solid, the females by broken lines. 
(2) In the majority of the groups of cases the height-weight indices of the males were above those of the females. However, the differences were so small that their significance is questionable.

(3) When the cases are arranged in groups according to centimeter intervals of body length the coefficients of variability in weight of these groups are found to range from 9.5 to 12.0. There is no regular change in the coefficients with increasing body length and no constant sex difference in the coefficient is noted.

The above conclusions were drawn from a study of the ponderal index as determined from the average weight for a given length. The difference between this figure and the average of the individual indices for a given length was tested by determining these two values separately for the 50 to $51 \mathrm{~cm}$. group which included 996 cases. In this group the height-weight index of the average height and weight was 25.99 per cent. (metric) for the males and 25.60 per cent. (metric) for the females. The average height-weight index was 26.01 per cent (metric) for the males and 25.60 per cent. (metric) for the females. The average ponderal index of the males showed a standard deviation of 2.41 and a coefficient of variability of 9.27 while that of the females showed a standard deviation of 2.26 and a coefficient of variability of 8.85 .

\section{1 (2011)}

Experimental demonstration of the entire course of four descending tracts ${ }^{1}$ by a single alcoholic injection in the mid-brain of the cat.

\section{By A. T. RASMUSSEN.}

[From the Department of Anatomy, Medical School, University of Minnesota, Minneapolis, Minnesota.]

By trephining a hole $2 \mathrm{~cm}$. in diameter, $1 \mathrm{~cm}$. anterior to the occipital crest and $2 \mathrm{~cm}$. from the median line, and retracting the occipital pole of the cerebral hemisphere of the cat, the superior colliculus was exposed and about two drops of 95 per

1 Fasciculus longitudinalis medialis, fasciculus tectospinalis, fasciculus rubrospinalis, radix mesencephaliea trigemini. 